\title{
Analysis of Factors Associated with Temporal Hollowing after Pterional Craniotomy
}

\author{
Thanakorn Thiensri ${ }^{1}$ Akaluk limpoka ${ }^{1}$ Chairat Burusapat ${ }^{2}$ \\ ${ }^{1}$ Division of Neurosurgery, Department of Surgery, \\ Phramongkutklao Hospital, Bangkok, Thailand \\ ${ }^{2}$ Division of Plastic and Reconstructive Surgery, Department \\ of Surgery, Phramongkutklao Hospital and Phramongkutklao \\ College of Medicine, Bangkok, Thailand

\begin{abstract}
Address for correspondence Chairat Burusapat, MD, FRCST, Division of Plastic and Reconstructive surgery, Department of Surgery, Phramongkutklao Hospital and Phramongkutklao College of Medicine, 315 Ratchawithi Road, Thung Phayathai, Ratchathewi,
\end{abstract} \\ Bangkok 10400, Thailand (e-mail: pataranat@hotmail.com)
}

Indian J Plast Surg 2020;53:71-82

\begin{abstract}
Background Temporal hollowing is a common complication after pterional craniotomy. Etiologies of hollowing are still in debate and inconclusive. The objective of this study is to determine the etiology and predictive factors of temporal hollowing after pterional craniotomy.

Methods A retrospective study of patients who underwent pterional craniotomy was conducted. Inclusion criteria included older than 18 years, having undergone unilateral pterional craniotomy, and with no craniofacial anomaly or temporal defect. Volumes of bone, temporalis muscle, and extratemporalis layer were calculated.

Results A total of 51 patients were included. Bone volumes of surgical and nonsurgical sites were $219.12+23.02 \mathrm{~cm}^{3}$, and $228.39+22.76 \mathrm{~cm}^{3}$, respectively $(p=0.04)$. Difference of bony volume was $9.10 \mathrm{~cm}^{3}(3.99 \%)$. Volumes of temporalis muscle in surgical and nonsurgical sites were $12.86+3.95 \mathrm{~cm}^{3}$, and $18.10+6.08 \mathrm{~cm}^{3}$, respectively $(p<0.005)$. Difference of muscle volume was $5.08 \mathrm{~cm}^{3}(28.32 \%)$. Volume of extratemporalis soft tissue in surgical and nonsurgical sites were $11.99+5.70 \mathrm{~cm}^{3}$, and $17.31+7.76 \mathrm{~cm} 3$, respectively $(p<0.005)$. Difference of soft tissue volume was $5.56 \mathrm{~cm}^{3}$ (31.68\%). No statistical significance of the difference of bony, muscle, and soft tissue volumes were found between causes of disease, operative time, and postoperative radiation.

Keywords

- etiology

- factor

- pterional craniotomy

- temporal hollowing

Conclusions Hollowing after pterional craniotomy is an unavoidable result. Bone, temporalis muscle, and soft tissues are combined etiologies. No predictive factors including age, sex, causes, operative time, radiation, and surgical technique are demonstrated. Volume of temporal area reduction was $19.74 \mathrm{~cm}^{3}$. Immediate reconstruction is recommended and volume of reconstruction is calculated from preoperative imaging.
\end{abstract}

\section{Introduction}

Pterional craniotomy is one of the most commonly performed procedures in neurosurgery and is used to treat cerebral aneurysms, arteriovenous malformations, and brain tumors. However, temporal hollowing is a frequent problem after pterional craniotomy. Hollowing is reported to occur following 87 to $100 \%$ of temporal craniotomy. ${ }^{1-4}$ Facial asymmetry between the surgical and nonsurgical sites as a result of temporal hollowing can cause the patient to experience lack of confidence and psychosocial problems.

Hypotheses have been established to determine the causes of temporal hollowing. However, controversy has arisen regarding whether the cause of temporal hollowing is atrophy of the temporalis muscle, atrophy or descent of the superficial temporal fat pad, injury to the frontotemporal

(C)2020 Association of Plastic Surgeons of India

License terms

10.1055/s-0040-1709953

ISSN 0970-0358.
DOI https://doi.org/ published onlin
April 23, 2020 
branch of facial nerve, or bone pits in the craniotomy line..$^{5-7}$ Ultimately, it remains inconclusive.

Several techniques have been proposed to address this problem, depending on the authors' hypotheses, such as split myofascial bone flap, interfascial pterional craniotomy, ${ }^{5}$ or avoidance of dissection beneath the superficial layer of deep temporal fascia or through the temporal fat pad. ${ }^{1}$ However, no gold standard has yet been identified with respect to the optimal surgical technique for preventing temporal hollowing after pterional craniotomy, because the actual etiologies of hollowing are still debated and inconclusive. This study's objective is to determine the etiology and predictive factors of temporal hollowing after pterional craniotomy.

\section{Material and Method}

Approval for this study was obtained from the ethics committee of Phramongkutklao Hospital and College of Medicine. A retrospective study of patients who underwent pterional craniotomy in Phramongkutklao Hospital between January 2016 and December 2018 was conducted. Inclusion criteria included age of over 18 years; experience of having undergone unilateral pterional craniotomy; absence of previous craniofacial anomaly, trauma, or surgery; and absence of previous temporal area defect or injury.

Exclusion criteria were experience of emergency surgery, advanced tumor with bony resection, absence of magnetic resonance imaging (MRI) and computed tomography (CT) performed before surgery, development of severe postoperative complications associated with the wound infection, dehiscence or necrosis, reoperation, and failure to fully regain consciousness within 6 months after surgery.

The database recorded age, sex, underlying disease, cause of disease, presenting symptoms, surgical technique, operative time, postoperative radiotherapy, and radiologic change. All patients were photographed in five views (front view, left and right oblique views, and left and right lateral views [-Fig. 1]).

Pterional craniotomy was defined by skin incision from the root of the zygoma along the superior temporal line to midscalp under the hairline. The tissue plane in the loose tissue layer underneath the subcutaneous layer was raised up to the frontozygomatic process. The temporalis muscle was divided and raised with the skin flap. Techniques for division

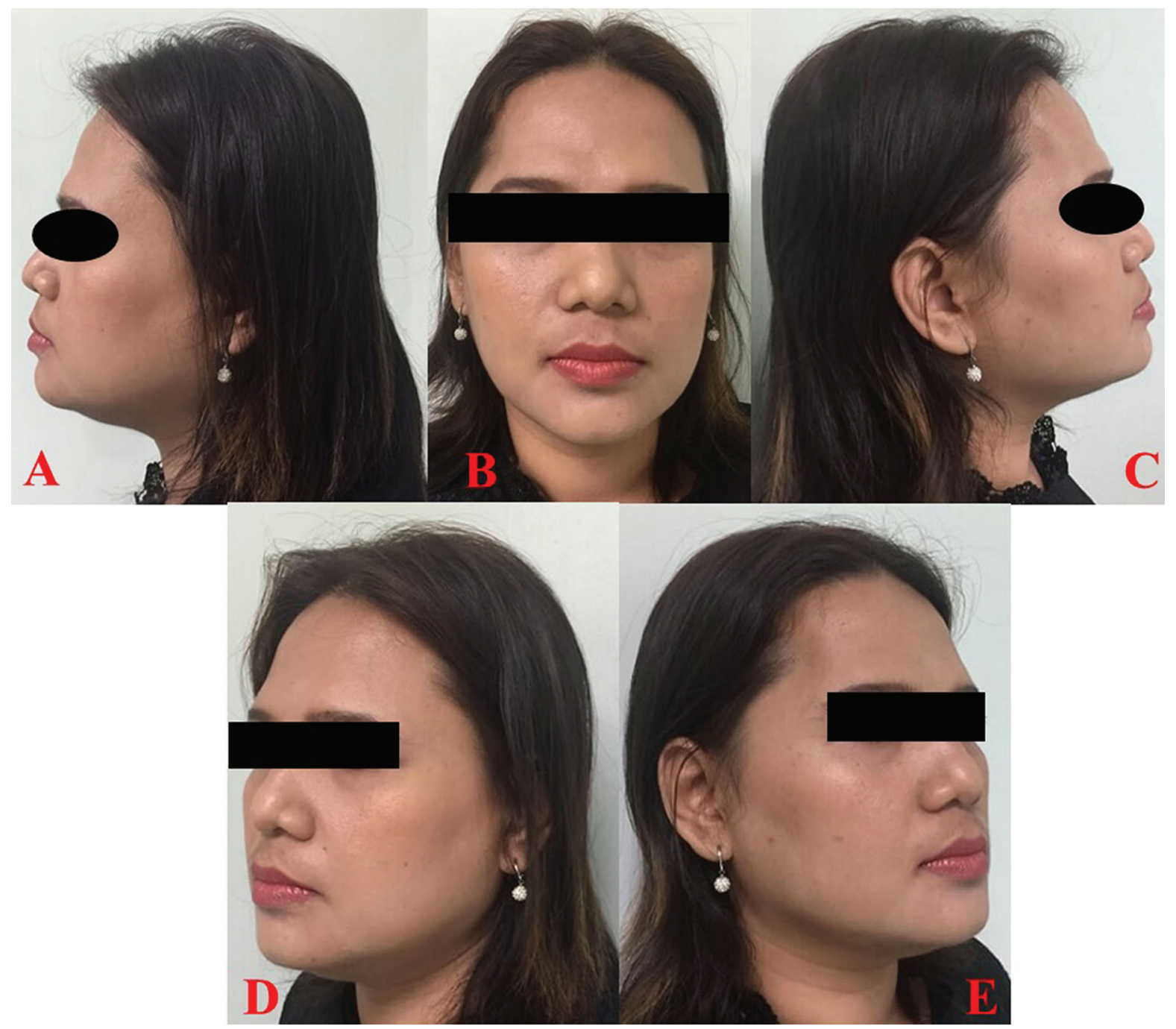

Fig. 1 Example of right temporal hollowing at 6 months postoperative following pterional craniotomy, compared with the left site. (a) Left lateral view, (b) front view, (c) right lateral view, (d) left oblique view, and (e) right oblique view. 
of the temporalis muscles are classified into two groups depending on the surgeon's preference: In group 1 part of the muscle is elevated leaving a cuff of temporalis muscle, while in group 2 the entire temporalis is elevated without leaving a cuff.

A burr hole was placed as a keyhole at the frontozygomatic process. The number of burr holes used depends on the surgeon's preference and the specific procedure being performed. Bone cutting was performed using a high-speed drill from the root of the zygoma along the superior temporal line up to the frontozygomatic process. After the operation, the bone was fixed with a plate and screw, and the temporalis muscle was reattached. Bone pits were used to fill the craniotomy sites. The surgical techniques were distinguished according to whether the temporalis muscle was elevated with or without leaving a cuff, the site and number of burr holes, and the methods used to reattach the temporalis muscle.

MRI and CT scans were performed before the operation, immediately postoperation, and 6 months postoperation. The volume of bone was calculated using IPLAN CRANIAL 3.0.6 BRAIN LABORATORY (Brainlab AG, Munich, Germany) based on the CT scans of both the left and right

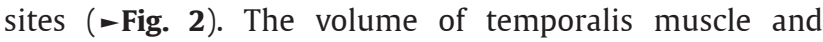
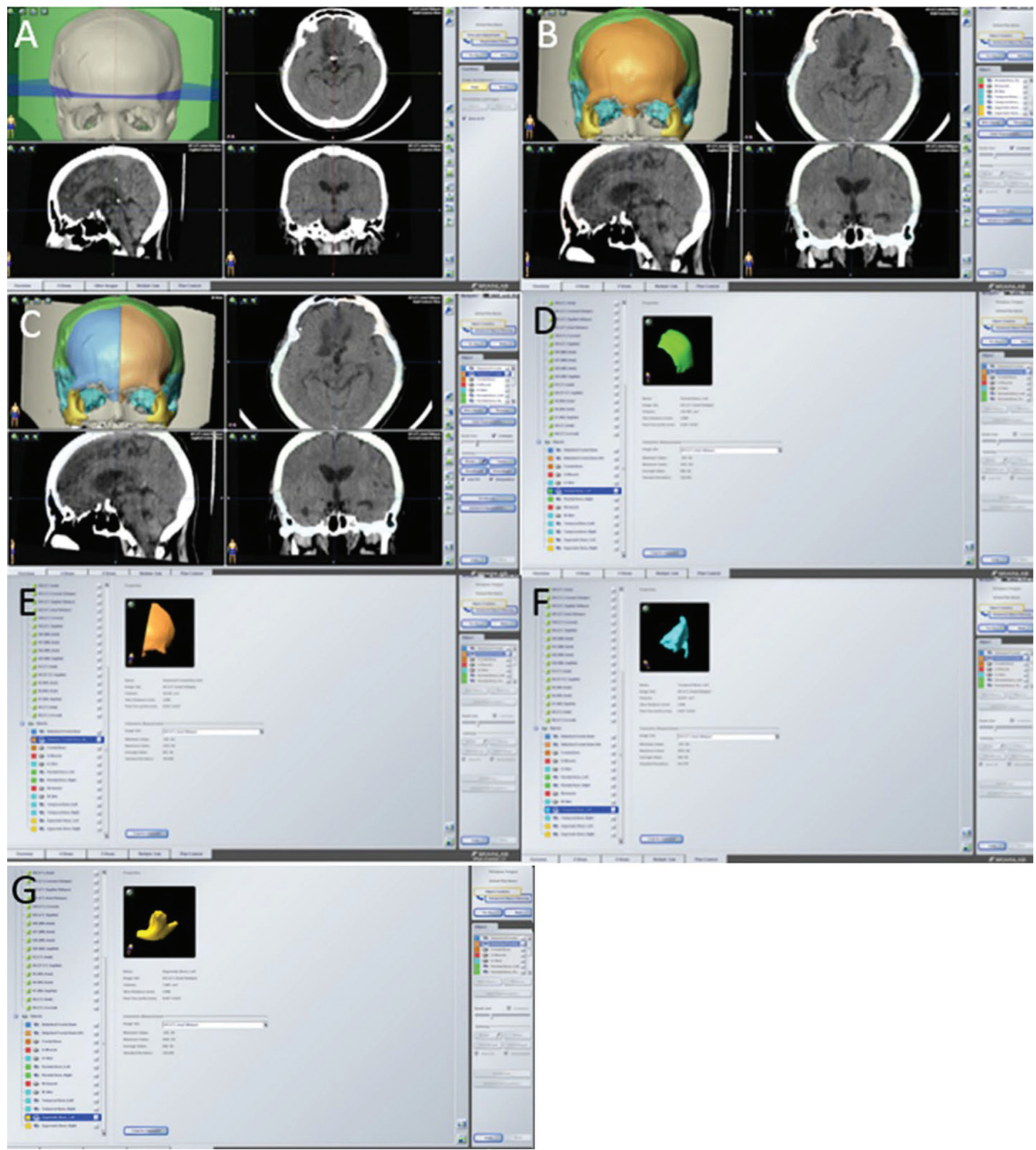

Fig. 2 (A) Bone volume of both left and right sites calculated from CT using IPLAN CRANIAL 3.0.6 BRAIN LABORATORY; (B) bone defined as frontal bone, parietal, temporal, and zygoma; (C) frontal bone divided at midline; (D) parietal bone; (E) frontal bone; (F) temporal bone; and (G) zygomatic bone. 
extratemporalis layer was calculated using IPLAN CRANIAL 3.0.6 BRAIN LABORATORY based on the MRI scans of both the left and right sites ( - Fig. $\mathbf{3}$ ). The extratemporalis layer is defined as all soft tissue lateral to the temporalis muscle, including skin and the subcutaneous layer. Bone is defined as frontal bone from the midline, parietal, temporal, and zygoma. In group 1, part of the muscle was elevated, leaving a cuff of temporalis muscle comprising at least $1 \mathrm{~cm}$ at the superior temporal line, and the temporal muscle was resutured upon completion of the procedure. In group 2, the entire temporalis muscle was elevated without leaving a cuff, dissected from the temporal bone at its origin, and reattached to the temporal bone by drilling the bone and fixing the muscle with nonabsorbable suture to the bone. The volumes of bone, temporalis muscle, and extratemporalis soft tissues were calculated, including the preoperative surgical site and postoperative surgical and nonsurgical sites.

\section{Statistical Analysis}

Correlations between the volumes of bone, temporalis muscle, and extratemporalis muscle and surgical technique were analyzed. The univariate analysis of the independent variables was accomplished using the chi-square test and independent $t$-test. A $p$-value of $<0.05$ was considered statistically significant.

\section{Results}

A total of 51 patients were included in the study. Thirtyfive patients were female (68.6\%). The patients' mean age was 52.1 years (range $20-77$ years). Sixteen patients had experienced operative times of more than 8 hours. Forty-four patients had three craniotomy burred holes. Sixteen patients had postoperative radiation. The average area of craniotomy was $153.85 \mathrm{~cm}^{2}$ (-Table $\mathbf{1}$ ).

Bone volumes of the preoperative and postoperative surgical and nonsurgical sites were $228.22 \pm 23.38 \mathrm{~cm}^{3}$, $219.12 \pm 23.02 \mathrm{~cm}^{3}$, and $228.39 \pm 22.76 \mathrm{~cm}^{3}$, respectively. Statistically significant difference in bone volume was observed between postoperative surgical and nonsurgical sites, as shown in - Table $\mathbf{2}$. The difference in the volume of bony tissue between surgical and nonsurgical sites was $9.10 \mathrm{~cm}^{3}$ (3.99\%). The volumes of the temporalis muscle in preoperative surgical, postoperative surgical, and nonsurgical sites were $17.94 \pm 7.01 \mathrm{~cm}^{3}, 12.86 \pm 3.95 \mathrm{~cm}^{3}$, and $18.10 \pm 6.08 \mathrm{~cm}^{3}$, respectively. Statistically significant differences in muscle volume were observed between postoperative surgical and nonsurgical sites, as shown in - Table 2 . The difference in temporalis muscle volume was $5.08 \mathrm{~cm}^{3}$ (28.32\%). The volumes of extratemporalis soft tissue in preoperative surgical, postoperative surgical, and nonsurgical sites were $17.55 \pm 7.93,11.99 \pm 5.70$, and $17.31 \pm 7.76 \mathrm{~cm}^{3}$, respectively. The statistical significance of extramuscular volume was found between postoperative surgical and nonsurgical sites, as shown in $\boldsymbol{- T a b l e} \mathbf{2}$. The difference in soft tissue volume lateral to the muscle was $5.56 \mathrm{~cm}^{3}$ (31.68\%) (-Table 2; - Fig. 4).

The difference in bony tissue volume was $8.08 \pm 5.19 \mathrm{~cm}^{3}$ in cases of aneurysm and $9.74 \pm 4.71 \mathrm{~cm}^{3}$ in cases of tumor. No statistically significant difference was observed in the volume of bony tissue between cases of aneurysm and tumor, as shown in - Table 3 . The difference in the volume of temporalis muscle was $7.76 \pm 10.19 \mathrm{~cm}^{3}$ in aneurysm cases, while it was $4.38 \pm 3.55 \mathrm{~cm}^{3}$ in cases of tumor. No statistically

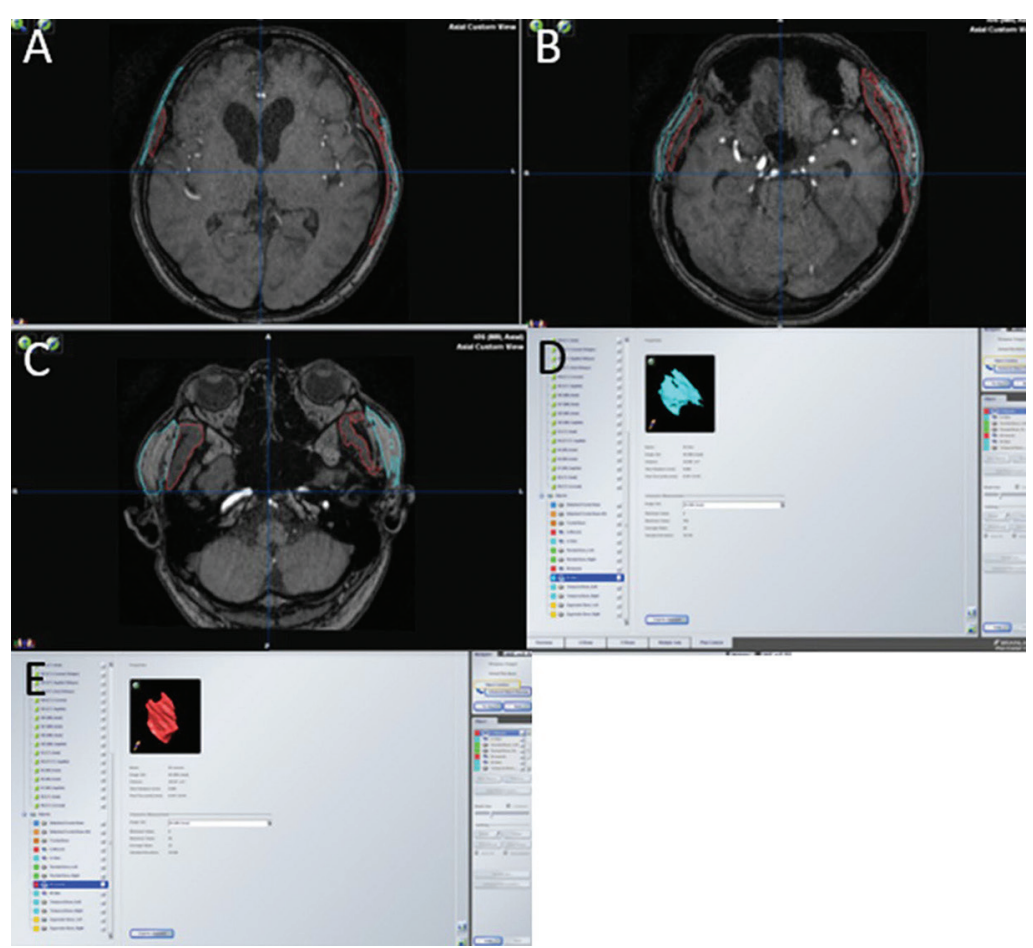

Fig. 3 (A-C) Volume of temporalis muscle and extratemporalis layer was calculated by IPLAN CRANIAL 3.0.6 BRAIN LABORATORY from MRI of both left and right sites; (D) extratemporalis layer; and (E) temporalis muscle. 
significant difference in muscle volume was observed between aneurysm and tumor, as shown in - Table 3. The difference in the volume of extratemporalis reduction was $4.83 \pm 3.43 \mathrm{~cm}^{3}$ in aneurysm cases and $5.47 \pm 5.07 \mathrm{~cm}^{3}$ in tumor cases. No statistically significant difference in extratemporalis soft tissue volume was observed between aneurysm and tumor cases, as shown in - Table 3 and - Fig. 5 .

Table 1 Demographic data

\begin{tabular}{|c|c|}
\hline Demographic data & $N(\%)$ \\
\hline \multicolumn{2}{|l|}{ Age } \\
\hline $20-40 y$ & $6(11 \%)$ \\
\hline $40-60$ y & $28(54.9 \%)$ \\
\hline $60-80 y$ & $17(33.3 \%)$ \\
\hline \multicolumn{2}{|l|}{ Gender } \\
\hline Male:female & 16 (31.37\%):35 (68.6\%) \\
\hline \multicolumn{2}{|l|}{ Surgical site } \\
\hline Right:left & 21 (41.17\%):30 (58.83\%) \\
\hline \multicolumn{2}{|l|}{ Cause } \\
\hline Vascular (aneurysm) & $13(25.4 \%)$ \\
\hline Tumor & $38(74.6 \%)$ \\
\hline \multicolumn{2}{|l|}{ Surgical technique } \\
\hline $\begin{array}{l}\text { Part of muscle elevated } \\
\text { leaving a cuff of tempora- } \\
\text { lis muscle }\end{array}$ & 37 (72.54\%) \\
\hline $\begin{array}{l}\text { Entire temporalis elevated } \\
\text { without leaving a cuff }\end{array}$ & $14(27.4 \%)$ \\
\hline \multicolumn{2}{|l|}{ Surgical time (h) } \\
\hline $0-8 \mathrm{~h}$ & 35 (68.63\%) \\
\hline$>8 \mathrm{~h}$ & $16(31.37 \%)$ \\
\hline \multicolumn{2}{|l|}{ Postoperative radiation } \\
\hline Yes & $16(31.37 \%)$ \\
\hline No & 35 (68.63\%) \\
\hline \multicolumn{2}{|l|}{ Number of burr holes } \\
\hline Three & $48(94.12 \%)$ \\
\hline Four & $3(5.88 \%)$ \\
\hline Area of craniotomy & $\begin{array}{l}153.85 \mathrm{~cm}^{2} \\
\left(75.00-225.00 \mathrm{~cm}^{2}\right) \\
(7.5 \times 10.0-15.0 \times 15.0 \mathrm{~cm})\end{array}$ \\
\hline
\end{tabular}

The difference in bony tissue volume in cases with operative times of less than 8 hours was $9.10 \pm 5.34 \mathrm{~cm}^{3}$ and in cases with operative times of more than eight hours it was $8.65 \pm 4.12 \mathrm{~cm}^{3}$. No statistically significant difference in bone volume was observed between operative times of less and more than 8 hours, as shown in - Table 3. The differences in the volume of temporalis muscle in operative times of less and more than 8 hours were $4.51 \pm 4.33 \mathrm{~cm}^{3}$ and $6.39 \pm$ $3.86 \mathrm{~cm}^{3}$, respectively. No statistically significant difference in muscle volume was observed between operative times of less and more than 8 hours, as shown in - Table 3. The differences in the volume of extratemporalis soft tissue in operative times of less and more than eight hours were 5.24 $\pm 5.43 \mathrm{~cm}^{3}$ and $5.74 \pm 4.35 \mathrm{~cm}^{3}$, respectively. No statistically significant difference in extratemporalis volume was observed between operative times of less and more than 8 hours, as shown in - Table 3 .

The difference in bony tissue volume in cases of postoperative radiation was $8.61 \pm 4.82 \mathrm{~cm}^{3}$, while in nonradiation cases it was $9.22 \pm 5.01 \mathrm{~cm}^{3}$. No statistically significant difference in bone volume was observed between cases of radiation and nonradiation, as shown in - Table 3. The differences in the volume of temporalis muscle in cases of postoperative radiation and nonradiation were $4.72 \pm$ $4.18 \mathrm{~cm}^{3}$ and $5.43 \pm 4.19 \mathrm{~cm}^{3}$, respectively. No statistically significant difference in muscle volume was found between cases of radiation and nonradiation, as shown in - Table $\mathbf{3}$. The difference in the volume of extratemporalis soft tissue in cases of postoperative radiation was $4.36 \pm 2.80 \mathrm{~cm}^{3}$, and that in cases of nonradiation was $5.90 \pm 4.81 \mathrm{~cm}^{3}$. No statistically significant difference in extratemporalis volume was observed between postoperative radiation and nonradiation cases, as shown in - Table 3.

The volumes of temporalis muscle in cases in which part of the muscle was elevated, leaving a cuff of temporalis muscle group for both postoperative surgical and nonsurgical sites were $13.62 \pm 4.30 \mathrm{~cm}^{3}$ and $18.36 \pm 6.55 \mathrm{~cm}^{3}$, respectively. Statistical significance was observed between postoperative surgical and nonsurgical sites in cases in which part of the muscle was elevated, leaving a cuff of temporalis muscle group, as shown in $\mathbf{- T a b l e} \mathbf{4}$ and $\boldsymbol{- F i g}$. 6 . The volumes of temporalis muscle in cases in which the entire temporalis was elevated without leaving a cuff group for both postoperative surgical and nonsurgical sites were $10.37 \pm 1.75 \mathrm{~cm}^{3}$

Table 2 Demonstrated the volume of bony, temporalis muscle, and extratemporalis soft tissue between preoperative surgical site, postoperative surgical site, and postoperative nonsurgical site

\begin{tabular}{|l|l|l|l|l|}
\hline Volume & $\begin{array}{l}\text { Preoperative } \\
\text { surgical site } \\
\text { (mean } \pm \text { standard } \\
\text { deviation) }\left(\mathrm{cm}^{3}\right)\end{array}$ & $\begin{array}{l}\text { Postoperative } \\
\text { surgical site } \\
\text { (mean } \pm \text { standard } \\
\text { deviation) }\left(\mathrm{cm}^{3}\right)\end{array}$ & $\begin{array}{l}\text { Postoperative } \\
\text { nonsurgical site } \\
\text { (mean } \pm \text { standard } \\
\text { deviation })\left(\mathrm{cm}^{3}\right)\end{array}$ & $p$-Value \\
\hline Bone & $228.22 \pm 23.38$ & $219.12 \pm 23.02$ & $228.39 \pm 22.76$ & 0.04 \\
\hline Temporalis muscle & $17.94 \pm 7.01$ & $12.86+3.95$ & $18.10 \pm 6.08$ & $<0.005$ \\
\hline Extratemporalis & $17.55 \pm 7.93$ & $11.99+5.70$ & $17.31+7.76$ & $<0.005$ \\
\hline
\end{tabular}

apaired $t$-test. A $p$-value of $<0.05$ was considered statistically significant. 


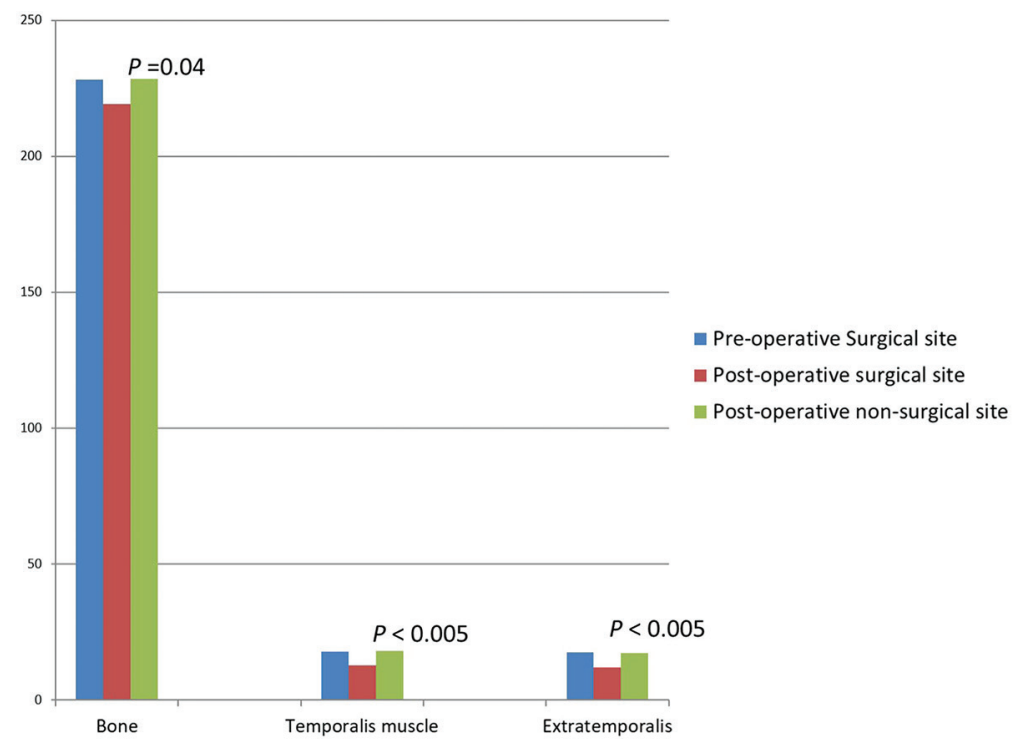

Fig. 4 Chart demonstrating the bone, temporalis muscle, and extratemporalis layer volumes of preoperative and postoperative pterional craniotomy sites and postoperative nonsurgical sites.

Table 3 Demonstrated the difference volume of bony, temporalis muscle, and extratemporalis soft tissue between postoperative surgical and nonsurgical sites

\begin{tabular}{|c|c|c|c|c|c|c|}
\hline Variables & $\begin{array}{l}\text { Bone } \\
\text { (mean } \pm \\
\text { standard } \\
\text { deviation) } \\
\left(\mathrm{cm}^{3}\right)\end{array}$ & p-Value* & $\begin{array}{l}\text { Temporalis } \\
\text { muscle } \\
\text { (mean } \pm \\
\text { standard } \\
\text { deviation) } \\
\left(\mathrm{cm}^{3}\right)\end{array}$ & $p$-Value ${ }^{a}$ & $\begin{array}{l}\text { Extratemporalis } \\
\text { (mean } \pm \\
\text { standard } \\
\text { deviation) }\left(\mathrm{cm}^{3}\right)\end{array}$ & $p$-Value ${ }^{a}$ \\
\hline \multicolumn{7}{|c|}{ Etiology of disease } \\
\hline Aneurysm & $8.08 \pm 5.19$ & \multirow[t]{2}{*}{0.18} & $7.76 \pm 10.19$ & \multirow[t]{2}{*}{0.28} & $4.83 \pm 3.43$ & \multirow[t]{2}{*}{0.38} \\
\hline Tumor & $9.74 \pm 4.71$ & & $4.38 \pm 3.55$ & & $5.47 \pm 5.07$ & \\
\hline \multicolumn{7}{|c|}{ Operative time } \\
\hline$<8 \mathrm{~h}$ & $9.10 \pm 5.34$ & \multirow[t]{2}{*}{0.38} & $4.51 \pm 4.33$ & \multirow[t]{2}{*}{0.09} & $5.24 \pm 5.43$ & \multirow[t]{2}{*}{0.38} \\
\hline$>8 \mathrm{~h}$ & $8.65 \pm 4.12$ & & $6.39 \pm 3.86$ & & $5.74 \pm 4.35$ & \\
\hline \multicolumn{7}{|l|}{ Radiation } \\
\hline Yes & $8.61 \pm 4.82$ & \multirow[t]{2}{*}{0.37} & $4.72 \pm 4.18$ & \multirow[t]{2}{*}{0.29} & $4.36 \pm 2.80$ & \multirow[t]{2}{*}{0.12} \\
\hline No & $9.22 \pm 5.01$ & & $5.43 \pm 4.19$ & & $5.90 \pm 4.81$ & \\
\hline
\end{tabular}

aPaired $t$-test. A $p$-value of $<0.05$ was considered statistically significant.

and $16.96 \pm 4.62 \mathrm{~cm}^{3}$, respectively. Statistical significance was observed between postoperative surgical and nonsurgical sites in cases in which the entire temporalis was elevated without leaving a cuff, as shown in - Table 4. The volume of temporalis muscle in cases in which the entire temporalis was elevated without leaving a cuff and those in which part of the muscle was elevated, leaving a cuff of temporalis muscle in postoperative surgical sites, were $13.62 \pm 4.30 \mathrm{~cm}^{3}$ and $10.37 \pm 1.75 \mathrm{~cm}^{3}$, respectively. Statistical significance was found in postoperative surgical sites in which the entire temporalis had been elevated without leaving a cuff and those in which part of muscle was elevated, leaving a cuff of temporalis muscle, as shown in - Table 4 . The volumes of temporalis muscle reduction in cases in which the entire temporalis had been elevated without leaving a cuff and those in which part of the muscle was elevated, leaving a cuff of temporalis muscle were $4.74 \mathrm{~cm}^{3}$ (25.82\%) and $6.59 \mathrm{~cm}^{3}$ (38.86\%), respectively.

The volumes of frontal bone in postoperative surgical and nonsurgical sites were $52.70 \pm 7.74 \mathrm{~cm}^{3}$ and $55.57 \pm 8.85 \mathrm{~cm}^{3}$, respectively, as shown in - Table $\mathbf{5}$. The volumes of parietal bone in surgical and nonsurgical sites were $116.98 \pm 13.29 \mathrm{~cm}^{3}$ and $120.56 \pm 13.05 \mathrm{~cm}^{3}$, respectively. The volumes of temporal bone in surgical and nonsurgical sites were $42.45 \pm 5.71 \mathrm{~cm}^{3}$ and $44.79 \pm 4.88 \mathrm{~cm}^{3}$, respectively. The volumes of zygomatic bone in surgical and nonsurgical sites 


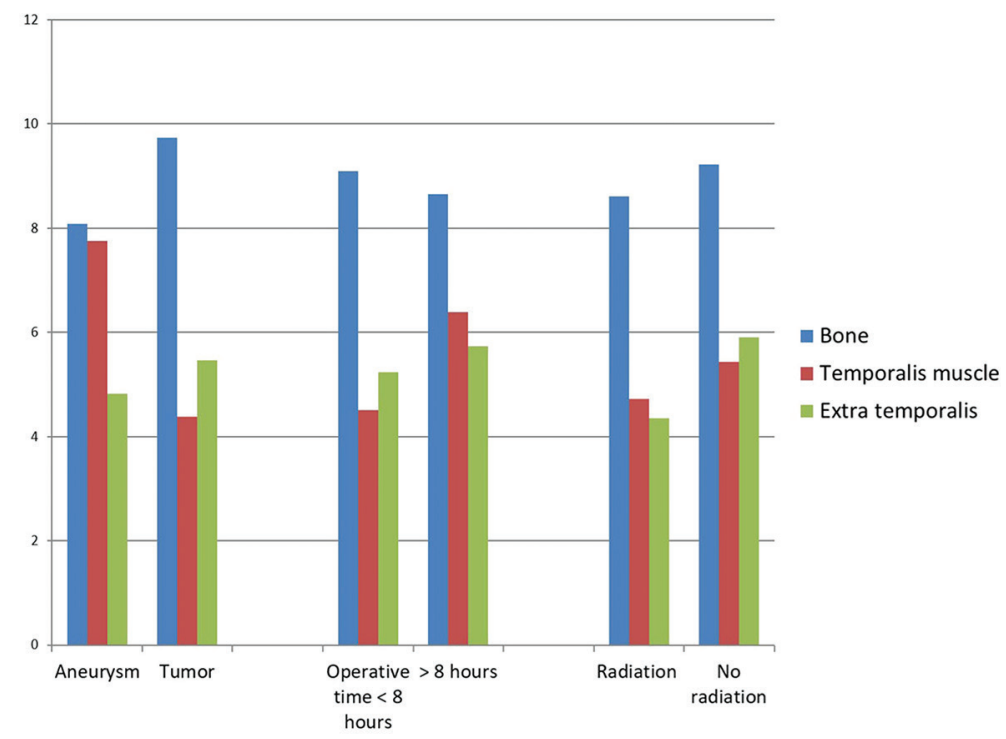

Fig. 5 Chart demonstrating the differences in volume of bony, temporalis muscle, and extratemporalis soft tissue with respect to disease, operative time, and postoperative radiation.

Table 4 Demonstrated the volume of temporalis muscle in postoperative pterional craniotomy between leave and nonleave cuff muscle

\begin{tabular}{|c|c|c|}
\hline & $\begin{array}{l}\text { Volume of } \\
\text { temporalis } \\
\text { muscle }\left(\mathrm{cm}^{3}\right) \\
\text { (mean } \pm \text { standard } \\
\text { deviation) }\end{array}$ & $p$-Value ${ }^{a}$ \\
\hline \multicolumn{3}{|c|}{$\begin{array}{l}\text { Part of muscle elevated leaving a cuff of temporalis muscle } \\
(n=37)\end{array}$} \\
\hline Surgical site & $13.62 \pm 4.30$ & \multirow[t]{2}{*}{$<0.001$} \\
\hline Nonsurgical site & $18.36 \pm 6.55$ & \\
\hline \multicolumn{3}{|c|}{ Entire temporalis elevated without leaving a cuff $(n=14)$} \\
\hline Surgical site & $10.37 \pm 1.75$ & \multirow[t]{2}{*}{0.005} \\
\hline Nonsurgical site & $16.96 \pm 4.62$ & \\
\hline \multicolumn{3}{|l|}{ Surgical site } \\
\hline $\begin{array}{l}\text { Part of muscle } \\
\text { elevated } \\
\text { leaving a cuff } \\
\text { of temporalis } \\
\text { muscle }(n=37)\end{array}$ & $13.62 \pm 4.30$ & \multirow[t]{2}{*}{0.001} \\
\hline $\begin{array}{l}\text { Entire tempo- } \\
\text { ralis elevated } \\
\text { without leaving } \\
\text { a cuff }(n=14)\end{array}$ & $10.37 \pm 1.75$ & \\
\hline
\end{tabular}

aPaired $t$-test. A $p$-value of $<0.05$ was considered statistically significant.

were $6.76 \pm 2.55 \mathrm{~cm}^{3}$ and $7.47 \pm 2.42 \mathrm{~cm}^{3}$, respectively. The total volumes of bony tissue in surgical and nonsurgical sites were $219.12 \pm 23.02 \mathrm{~cm}^{3}$ and $228.39 \pm 22.76 \mathrm{~cm}^{3}$, respectively. Statistically significant differences in the bony tissue volume between postoperative surgical and nonsurgical sites were observed in total bony tissue and temporal bone volumes ( - Table 5; - Fig. 7). Statistically significant differences in the volume of temporalis muscle between groups with the entire temporalis elevated without leaving a cuff and those in which part of the muscle was elevated, leaving a cuff of temporalis muscle, were observed in patients who had experienced aneurysms and without postoperative radiation, as shown in $\mathbf{- T a b l e} \mathbf{6}$ and $\boldsymbol{- \text { Fig. }}$. 8. No statistically significant differences in bony tissue volume were observed between surgical and nonsurgical sites with respect to each factor, as shown in -Table 7 and - Fig. 9.

\section{Discussion}

The incidence of hollowing after temporal craniotomy is reportedly 87 to $100 \% .^{1-4}$ All patients in our study showed temporal hollowing after pterional craniotomy. The patients reported feeling that this is a hallmark of neurosurgery aimed at treating neurological disorders and that it can cause psychosocial problems. Many methods have been developed to rectify this outcome, including both prophylactic and therapeutic modalities. Controversy has arisen regarding whether the cause of hollowing originates in soft tissue or bony tissue. ${ }^{6}$

Temporalis muscle atrophy has been suggested as a possible cause of hollowing, and several methods of preserving the temporalis muscle have been proposed. The factors that contribute to muscle atrophy include denervation, ischemia, muscle injury, and improper repositioning or resuspension of muscle. ${ }^{8,9}$ Prophylactic surgical techniques for temporal hollowing have been reported, including splitting of the myofascial bone flap, ${ }^{5}$ retrograde dissection of the temporalis muscle, ${ }^{8}$ subfascial dissection, and posterior displacement of the temporalis muscle without muscular incision. ${ }^{10}$

Kadri and Al-Mefty have recommended several steps for preserving the temporal muscle, including preserving the 


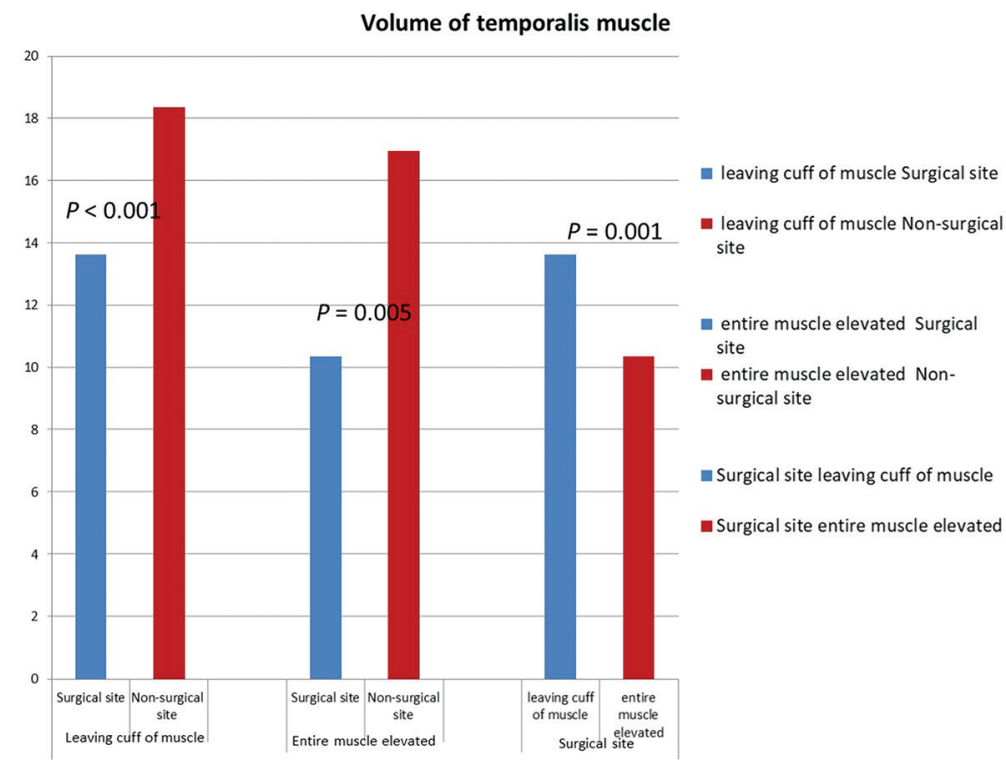

Fig. 6 Chart demonstrating the volume of temporalis muscle in postoperative pterional craniotomy and nonsurgical sites in cases in which the entire temporalis was elevated without leaving a cuff and those in which part of the muscle was elevated leaving a cuff of temporalis muscle.

Table 5 Demonstrated the bony volume in different sites of postoperative pterional craniotomy between surgical and nonsurgical sites

\begin{tabular}{|l|l|l|l|}
\hline Bone site & $\begin{array}{l}\text { Surgical site }\left(\mathrm{cm}^{3}\right) \\
\text { (mean } \pm \text { standard deviation) }\end{array}$ & $\begin{array}{l}\text { Nonsurgical site }\left(\mathrm{cm}^{3}\right) \\
(\text { mean } \pm \text { standard deviation) }\end{array}$ & $p$-Value \\
\hline Frontal & $52.70 \pm 7.74$ & $55.57 \pm 8.85$ & 0.06 \\
\hline Parietal & $116.98 \pm 13.29$ & $120.56 \pm 13.05$ & 0.11 \\
\hline Temporal & $42.45 \pm 5.71$ & $44.79 \pm 4.88$ & 0.02 \\
\hline Zygoma & $6.76 \pm 2.55$ & $7.47 \pm 2.42$ & 0.10 \\
\hline Total & $219.12 \pm 23.02$ & $228.39 \pm 22.76$ & 0.04 \\
\hline
\end{tabular}

aPaired $t$-test. A $p$-value of $<0.05$ was considered statistically significant.

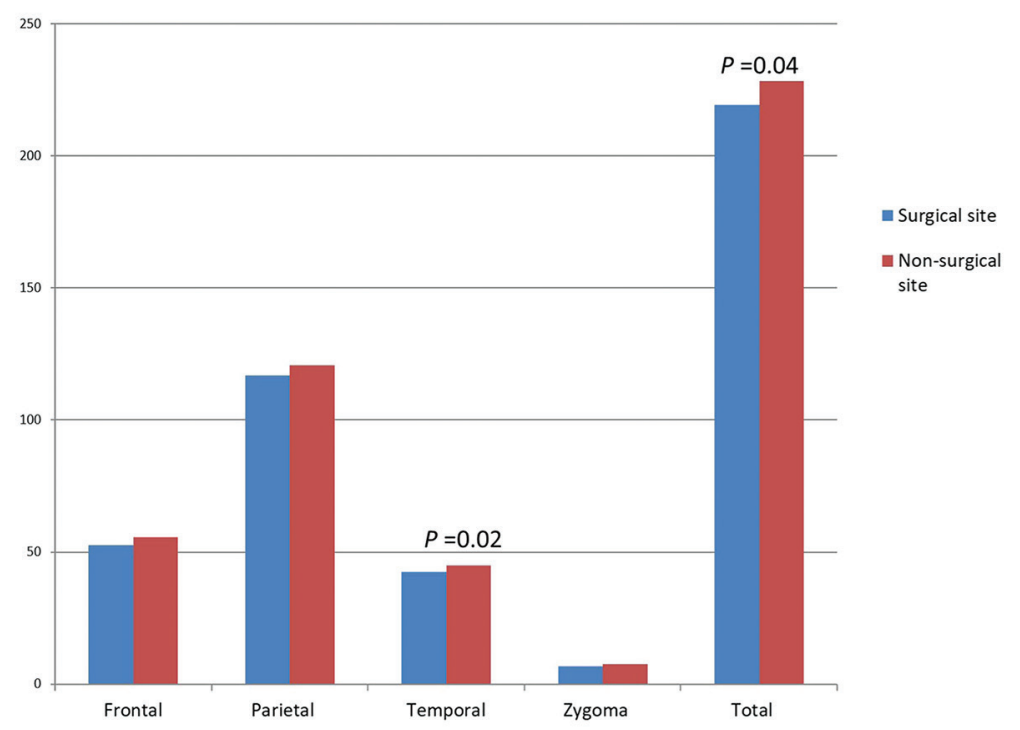

Fig. 7 Chart demonstrating the postoperative volumes of frontal, parietal, temporal, and zygomatic bones following pterional craniotomy at surgical and nonsurgical sites. 
Table 6 Demonstrated the volume of postoperative pterional craniotomy temporalis muscle between part of muscle elevated, leaving a cuff of temporalis muscle, and entire temporalis elevated without leaving a cuff in each factors

\begin{tabular}{|c|c|c|c|}
\hline & $\begin{array}{l}\text { Part of muscle elevated } \\
\text { leaving a cuff of temporalis } \\
\text { muscle ( } n=37 \text { ) } \\
\text { (mean } \pm \text { standard deviation) } \\
\left(\mathrm{cm}^{3}\right)\end{array}$ & $\begin{array}{l}\text { Entire temporalis elevated } \\
\text { without leaving a cuff } \\
\text { ( } n=14) \\
\text { (mean } \pm \text { standard deviation) } \\
\left(\mathrm{cm}^{3}\right)\end{array}$ & $p$-Value ${ }^{a}$ \\
\hline \multicolumn{4}{|l|}{ Etiology of disease } \\
\hline Aneurysm $(n=13)(8: 5)$ & $16.03 \pm 6.38$ & $10.42 \pm 1.22$ & 0.04 \\
\hline Tumor $(n=38)(29: 9)$ & $13.33 \pm 3.95$ & $11.24 \pm 2.96$ & 0.06 \\
\hline \multicolumn{4}{|l|}{ Operative time } \\
\hline$<8$ h; $35(26: 9)$ & $12.91 \pm 3.72$ & $11.02 \pm 2.81$ & 0.09 \\
\hline$>8 \mathrm{~h} ; 16(11: 5)$ & $13.17 \pm 4.37$ & $16.73+4.28$ & 0.11 \\
\hline \multicolumn{4}{|l|}{ Radiation } \\
\hline Yes $16(10: 6)$ & $10.67 \pm 4.02$ & $11.63 \pm 3.06$ & 0.36 \\
\hline No $35(27: 8)$ & $14.75 \pm 3.57$ & $10.34 \pm 2.19$ & 0.01 \\
\hline
\end{tabular}

apaired $t$ test. A $p$-value of $<0.05$ was considered statistically significant.

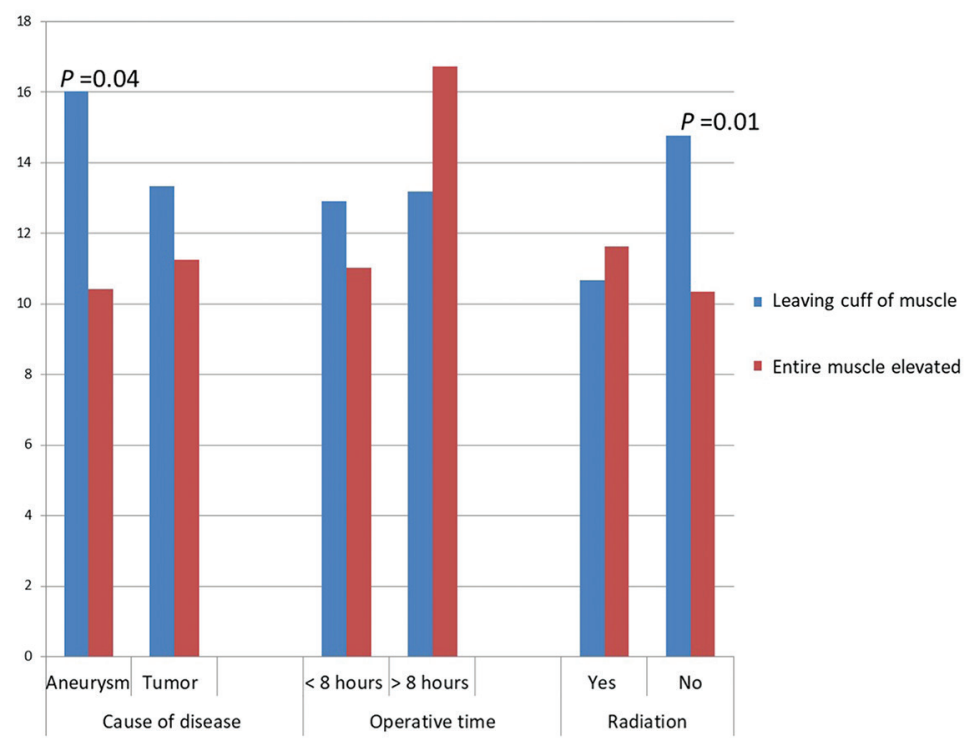

Fig. 8 Chart demonstrating the postoperative volumes of temporalis muscle following pterional craniotomy in cases in which the entire temporalis was elevated without leaving a cuff and those in which part of the muscle was elevated leaving a cuff of temporalis muscle with respect to disease, operative time, and postoperative radiation.

superficial temporal artery; prevention of injury to facial branches using subfascial dissection; zygomatic osteotomy to avoid compressing the muscle, arteries, and nerves; dissection of the muscle in subperiosteal retrograde fashion to preserve the deep vessels and nerves; deinsertion of the muscle to the superior temporal line without cutting the fascia; and reattachment of the muscle directly to the bone. ${ }^{9}$ To prevent improper positioning of the dissected temporal muscle, various fixation methods have been reported such as using a muscle cuff, ${ }^{11}$ microscrews fixation, ${ }^{12}$ and holes drilled into the bone graft. ${ }^{13}$
Our study showed that the decrease in the volume of temporalis muscle after surgery was statistically significant and that the average volume reduction was $5.08 \mathrm{~cm}^{3}$ (28.32\%). However, the volume of temporalis muscle reduction in cases in which part of the muscle was elevated, leaving a cuff of temporalis muscle, was lower than that in cases in which the entire temporalis was elevated without leaving a cuff.

Several authors have claimed that atrophy or descent of the superficial fat pad may cause temporal hollowing. The pathophysiology of superficial temporal fat pad atrophy is caused by ischemia, displacement, or denervation., ${ }^{9,14,15}$ The fat pad has been qualitatively demonstrated to be atrophic 


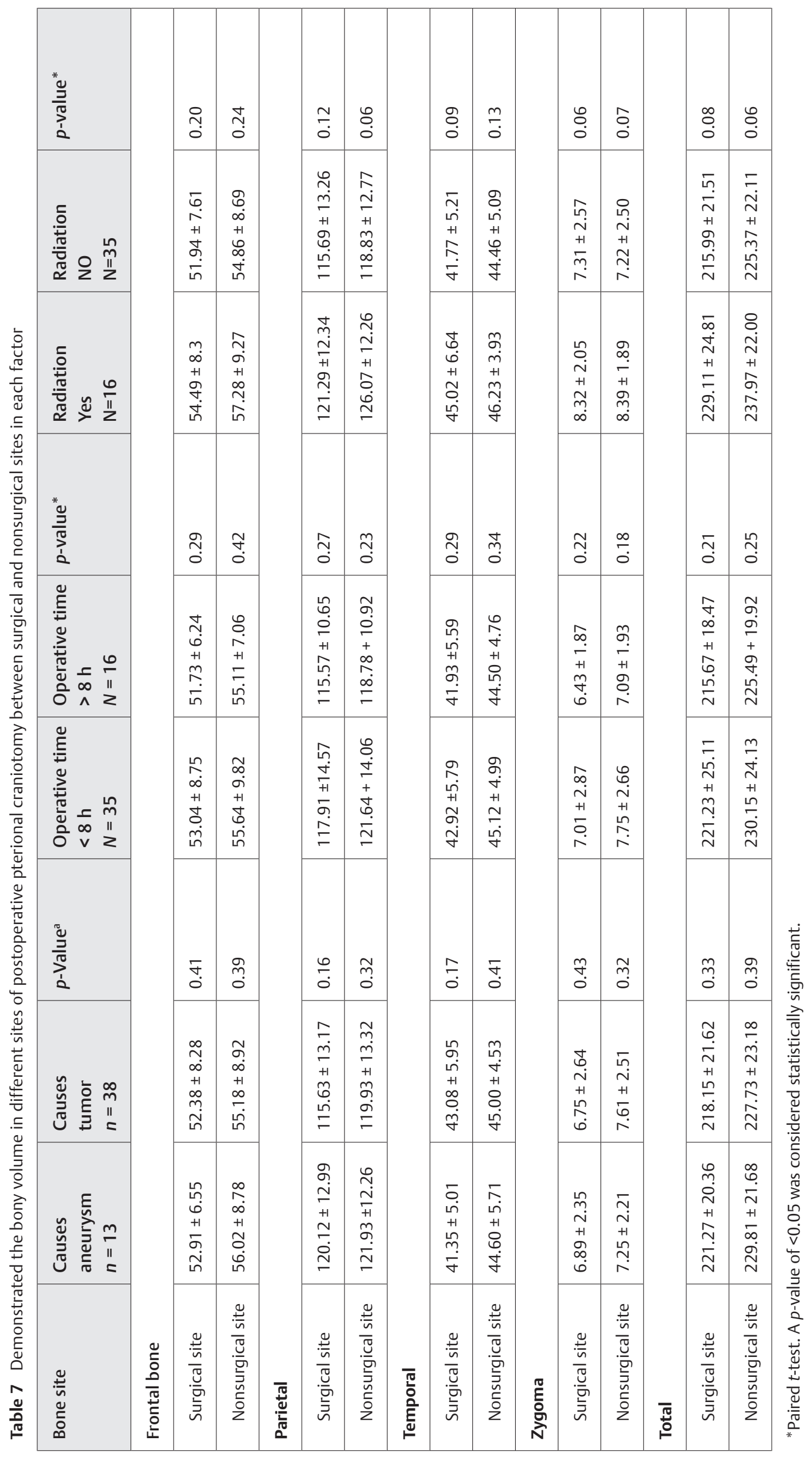




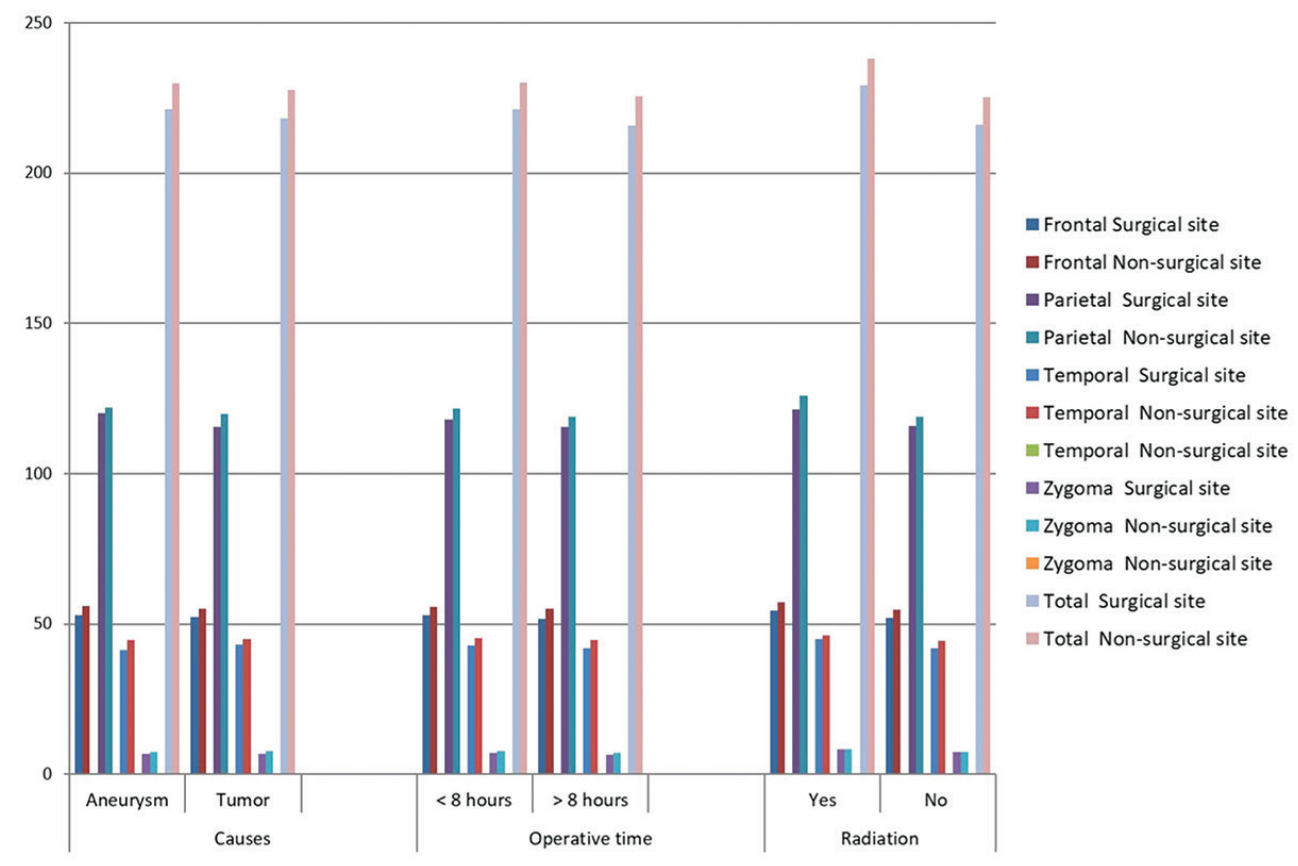

Fig. 9 Chart demonstrating the postoperative bony tissue volume following pterional craniotomy at surgical and nonsurgical sites with respect to disease, operative time, and postoperative radiation.

or ptotic in an earlier study. ${ }^{16}$ However, no study has determined the precise volume of fat pad that would contribute significantly to temporal hollowing. It is difficult to precisely determine the volume of the temporal fat pad using MRI; so, we decided to use all soft tissues lateral to the temporalis muscle in our study. Our study showed that the reduction in extratemporalis muscle volume was statistically significant at $5.56 \mathrm{~cm}^{3}$ (31.68\%).

Some reports have argued that the most common cause of temporal hollowing is bony defect of the pterional and temporal regions due to the resection of the sphenoid ridge and temporal squama for adequate exposure. ${ }^{17}$ However, no data have yet been produced to support this hypothesis. Our study showed that the average bony volume reduction was $9.10 \mathrm{~cm}^{3}$ (3.99\%).

At present, no gold standard for surgical technique has been developed to prevent temporal hollowing after pterional craniotomy. Both immediate and late reconstructions of the temporal area have been reported, with many materials, including autogenous and nonbiologic materials, used. ${ }^{14,17-24}$ No definitive implants have demonstrably yielded the best results.

Late reconstruction is the most commonly used method in patients who are concerned about temporal hollowing. Immediate reconstruction is another option, though it is less popular as it involves increased operative time and greater risk of postoperative complication; furthermore, it is difficult to calculate the requisite volume for reconstruction.

Our study revealed that temporal hollowing is an inevitable outcome following pterional craniotomy. The combined components of temporal bone, temporalis muscle, temporal fat pad, and subcutaneous tissue are the etiologies of the hollowing. Reduction in bony tissue volume can occur as a result of pitting and/or bone flap resorption. The volume of temporalis muscle reduction was evident both in cases in which the entire temporalis was elevated without leaving a cuff, and those in which part of the muscle was elevated leaving a cuff of temporalis muscle groups. However, the former group exhibited greater volume reduction than the latter group. Causes of temporalis muscle atrophy may include postsurgical scarring, denervation, or ischemia. Extratemporalis soft tissue reduction may result from postoperative scarring, temporal fat descent, or devascularization. The reduction in temporal area volume was $19.74 \mathrm{~cm}^{3}$. Bony, temporalis, and extratemporalis muscle volume reduction were 9.10 (3.99\%), $5.08(28.32 \%)$, and $5.56 \mathrm{~cm}^{3}$ (31.68\%), respectively. The data presented in this study will serve as a guideline for calculating the volume of temporal depressions and will thus be beneficial for immediate reconstruction procedures.

\section{Conclusions}

Temporal hollowing is an inevitable outcome following pterional craniotomy. Bony, temporalis muscle, and soft tissue are combined etiologies. No predictive factors, such as age, sex, causes of disease, time of operation, postoperative radiation, or surgical technique, have been identified. However, cases in which part of the muscle was elevated, leaving a cuff of temporalis muscle, exhibited less reduction in muscle volume than those in which the entire temporalis was elevated without leaving a cuff. The average volume of temporal area reduction was $19.74 \mathrm{~cm}^{3}$. Immediate reconstruction is 
recommended and the volume of reconstruction may be calculated based on preoperative imaging.

\section{Note}

American Society of Plastic Surgery International Member ID 142762.

\section{Financial Disclosure Statement}

The authors have no financial interest in any of the products or devices mentioned in this article.

\section{Trial Database Registered}

Thai Clinical Trials Registry (TCTR) (Member of WHO Registry Network). Registration Number: TCTR20191011002.

\section{Competing Interests}

The authors declare that they have no competing interests.

\section{Funding}

No funding source.

\section{Conflicts of Interest}

None declared.

\section{Acknowledgment}

The authors thank Supak Cae-ngow, statistician and research assistant at the Office of Research Development at Phramongkutklao College of Medicine, for the kind help with the statistical analysis of this article.

\section{References}

1 Vaca EE, Purnell CA, Gosain AK, Alghoul MS. Postoperative temporal hollowing: is there a surgical approach that prevents this complication? A systematic review and anatomic illustration. J Plast Reconstr Aesthet Surg 2017;70(3):401-415

2 de Andrade Júnior FC, de Andrade FC, de Araujo Filho CM, Carcagnolo Filho J. Dysfunction of the temporalis muscle after pterional craniotomy for intracranial aneurysms. Comparative, prospective and randomized study of one flap versus two flaps dieresis. Arq Neuropsiquiatr 1998;56(2):200-205

3 Kim E, Delashaw JB Jr. Osteoplastic pterional craniotomy revisited. Neurosurgery 2011;68(1(Suppl Operative) :125-129, discussion 129

4 Park J, Hamm IS. Cortical osteotomy technique for mobilizing the temporal muscle in pterional craniotomies. Technical note. J Neurosurg 2005;102(1):174-178

5 Matsumoto K, Akagi K, Abekura M, Ohkawa M, Tasaki O, Tomishima T. Cosmetic and functional reconstruction achieved using a split myofascial bone flap for pterional craniotomy. Technical note. J Neurosurg 2001;94(4):667-670

6 Steinbacher DM, Wink J, Bartlett SP. Temporal hollowing following surgical correction of unicoronal synostosis. Plast Reconstr Surg 2011;128(1):231-240
7 Badie B. Cosmetic reconstruction of temporal defect following pterional [corrected] craniotomy. Surg Neurol 1996;45(4):383-384

8 Oikawa S, Mizuno M, Muraoka S, Kobayashi S. Retrograde dissection of the temporalis muscle preventing muscle atrophy for pterional craniotomy. Technical note. J Neurosurg 1996;84(2): 297-299

9 Kadri PA, Al-Mefty O. The anatomical basis for surgical preservation of temporal muscle. J Neurosurg 2004;100(3):517-522

10 Miyazawa T. Less invasive reconstruction of the temporalis muscle for pterional craniotomy: modified procedures. Surg Neurol 1998;50(4):347-351, discussion 351

11 Spetzler RF, Lee KS. Reconstruction of the temporalis muscle for the pterional craniotomy. Technical note. J Neurosurg 1990t;73(4):636-637

12 Zager EL, DelVecchio DA, Bartlett SP. Temporal muscle microfixation in pterional craniotomies. Technical note. J Neurosurg 1993;79(6):946-947

13 Brunori A, DiBenedetto A, Chiappetta F. Transosseous reconstruction of temporalis muscle for pterional craniotomy: technical note. Minim Invasive Neurosurg 1997;40(1):22-23

14 Jin HB, Chung JH, Kim KS, Kim SH, Choe J, Yang JY. Reconstruction of temporal hollowing using two alloplastic materials simultaneously with titanium mesh and a silicone implant. Arch Aesthetic Plast Surg 2019;25:37-41

15 Kim S, Matic DB. The anatomy of temporal hollowing: the superficial temporal fat pad. J Craniofac Surg 2005;16(4):651-654

16 Lacey M, Antonyshyn O, MacGregor JH. Temporal contour deformity after coronal flap elevation: an anatomical study. J Craniofac Surg 1994;5(4):223-227

17 Kim YS, Yi HS, Kim HK, Han YS. Effectiveness of temporal augmentation using a calvarial onlay graft during pterional craniotomy. Arch Plast Surg 2016;43(2):204-209

18 McNichols $\mathrm{CH}$, Hatef DA, Cole P, Hollier LH, Thornton JF. Contemporary techniques for the correction of temporal hollowing: augmentation temporoplasty with the classic dermal fat graft. J Craniofac Surg 2012;23(3):e234-e238

19 Rapidis AD, Day TA. The use of temporal polyethylene implant after temporalis myofascial flap transposition: clinical and radiographic results from its use in 21 patients. J Oral Maxillofac Surg 2006;64(1):12-22

20 Gosain AK. Hydroxyapatite cement paste cranioplasty for the treatment of temporal hollowing after cranial vault remodeling in a growing child. J Craniofac Surg 1997;8(6):506-511

21 Burstein FD, Cohen SR, Hudgins R, Boydston W. The use of porous granular hydroxyapatite in secondary orbitocranial reconstruction. Plast Reconstr Surg 1997;100(4):869-874

22 Cheung LK, Samman N, Tideman H. The use of mouldable acrylic for restoration of the temporalis flap donor site. J Craniomaxillofac Surg 1994;22(6):335-341

23 Lacey M, Antonyshyn O. Use of porous high-density polyethylene implants in temporal contour reconstruction. J Craniofac Surg 1993;4(2):74-78

24 Mericli AF, Gampper TJ. Treatment of postsurgical temporal hollowing with high-density porous polyethylene. J Craniofac Surg 2014;25(2):563-567 